\title{
Local development and cultural landscapes: getting to know the inaccessible villages of the greek war of independence
}

\author{
Efrossyni Tsakiri ${ }^{1 *}[0000-0003-2348-2914]$, Maria Markou $^{1}$, Konstantinos Moraitis $^{2}$, and Helene Haniotou ${ }^{1}$ \\ ${ }^{1}$ NTUA, Dept. II Urban and Regional Planning, 10682 Athens, Greece \\ ${ }^{2}$ NTUA, Dept. III Architectural Language, Communication and Design, 10682 Athens, Greece
}

\begin{abstract}
The cultural landscapes have a dual, material and intangible nature being the result of interactions between people and nature through time. Considering that its understanding requires integrated analysis techniques we experimented a mapping method in «Revolutionary Palimpsests», a research project investigating the cultural landscapes of settlements that played an important role in the Greek War of Independence. Combining design, cartography and visual arts and focusing on socio-spatial complexities, our researchers produced maps of both artistic and informative nature revealing the mnemonic traces of such a historical event on those settlements. Maps' exhibition in a visual art event is expected to sensitize the public to that local heritage. We argue that the protection and promotion of the cultural landscape plays a significant role in development, strengthening the local identity and commitment, also enhancing the attractiveness, that is essential especially for inaccessible settlements that are facing development deficiencies, such as many mountainous and island settlements in Greece. From about 150 mapped «revolutionary settlements» we will refer below to the example of two inaccessible areas, Souli in Epirus and Mani (Maina) in Peloponnese, exploring the question of whether the protection and promotion of their cultural landscape could contribute to development.
\end{abstract}

Keywords. Cultural heritage, cultural landscape, mapping, sustainable development.

\section{Introduction}

Architecture is an aesthetic and socio-technical construction that arises from the interaction of people with each other and with artifacts as the result of the circulation of ideas and the application of technology for the production of the built environment. The settlement, in every scale (village, town, city) according to A. Rossi (1966), is a large-scale architectural work, a collective construction intertwined with society that has a long life, which is defined, signified by and interacting with society as a whole [1]. In this sense, it is a potentially «urban» place. Hillier (2009) also describes the settlement as consisting of three interacting sets, the material complex, its people, and the intangible networks of relationships and actions [2]. It is therefore obvious that settlements are determined both by their material elements and a multitude of intangible and

*Corresponding author: eftsakiri@gmail.com 
hidden elements and processes. They reflect the people who produce, transform, develop and exploit them and vice versa people evolve through their interaction with settlements.

As architecture itself, the cultural landscape of a settlement is a socio-technical construction with a dual nature: on the one hand it refers to its material, measurable and visible components while on the other hand it contains various intangible, invisible, qualitative, informal and non-measurable elements. We define it as «the material background of a place, natural or human-made together with any manifestation of the culture that emerges from it» (Moraitis, 2014) [3]. In the European Landscape Convention, landscape is referred to as «an area as perceived by the people, whose character is the result of the action and interaction of natural and/or human factors». The UNESCO World Heritage Committee (1992, 1996, 2002, 2011) $)^{\dagger}$ defines cultural landscapes as «geographical areas, which represent the combined work of nature and man. They depict the evolution of human society over time, under the influence of physical limitations and/or the possibilities of their natural environment, but also of successive social, economic and cultural forces, both external and internal». In the Declaration on Heritage Landscapes $(2004,2009)^{\ddagger}$, the International Council on Monuments and Sites (ICOMOS) describes cultural landscapes as diverse sets, at different scales, evolving over time from human-nature interaction. They are alive, changing and depending on changes, of the natural environment, the material and intangible cultural and historical elements and the people's values.

\subsection{Mapping of cultural landscapes and local development}

A necessary condition for the understanding and management of cultural landscapes is their in-depth knowledge. We argue that mapping and representation by visual and other means contribute significantly to the exploration and understanding of the cultural landscapes, especially to the extent that it highlights its experiential and emotional consonances. The choice of tools such as mapping and visualization is extremely important. Mapping means selecting, excluding, subtracting and sorting. Every map is therefore an inevitably subjective procedure based on the determination of what is important and insignificant, applied in the multiple data that identify space [4]. And since all management strategies are using maps as their basis, maps need to fulfil certain requirements: explore deeply all causes (analysis), investigate facts in a wide time range, relate places to each other and indicate possible networks, ensure the completeness of the study, detect as many as possible combinations and correlations [5]. All that will ultimately be the basis for an integrated development policy§. Visualization, respectively, should conclusively convey the data collected by the mapping, be inclusive and understandable for the targeted public.

The management of cultural landscapes i.e., its study, enhancement and promotion is necessary for the support and sustainable development of a settlement, for the integrated

\footnotetext{
†NESCO World Heritage Committee, 1992, Definitions of Cultural Landscapes (taken from the Convention Concerning the Protection of the World Cultural and Natural Heritage, 1972) - UNESCO, 1996, Operational Guidelines for the implementation of the World Heritage Convention, Paris - UNESCO, 2002, Cultural landscapes: the challenges of Conservation, World Heritage Papers, World Heritage 2002, Ferrara, Italy (edited 2003). UNESCO, 2011, Operational guidelines for the implementation of the World Heritage Convention, http://whc.unesco.org/archive/opguide11-en.pdf.

ICOMOS, 2004, Natchitoches Declaration on Heritage Landscapes, adopted at US/ICOMOS $7^{\text {th }}$ International Symposium at Natchitoches, www.nps.gov/mabi/csi/pdf/Natchitoches-Declaration-on-Heritage-Landscapes-304.pdf ICOMOS, 2009, World Heritage Cultural Landscapes, UNESCO-ICOMOS Documentation Centre

${ }^{\S}$ Integrated development that utilizes all the dynamics of the place and emphasizes that interconnection and diversity is a contemporary and acceptable approach, and today preferred to the sectorial development that supports vertical intervention. In addition, local development, which is a bottom-up approach and emphasizes endogenous development based on the potential of an area and not on external interventions, is today a predominant model (Bagineta, 2009). Enhancing the cultural potential of a place is an integrated approach, as it includes a variety of elements. It is also local, as it exploits the resources of the area and strengthens it.
} 
economic, social, environmental, cultural activation of its endogenous resources (Bagineta, 2009) [6]. Culture, in general, as it concentrates the material, social, emotional, mental, spiritual and ideological action of humans, is an invaluable legacy that must be preserved for future generations ${ }^{* *}$. Enhancing and promoting cultural landscapes is enshrined in all local, national, European and international policies and conventions. The European Landscape Convention, in particular, states that «the landscape has an important public interest role in the cultural, ecological, environmental and social fields, and constitutes a resource favourable to economic activity and whose protection, management and planning can contribute to job creation» and «it contributes to the formation of local cultures, to human, individual and social well-being, to the definition of European identity, to the quality of life for people, to the aesthetic quality of settlements, etc.». ${ }^{\dagger}$

\subsection{Protection and enhancement strategies for the cultural landscape of the inaccessible settlements}

The need to protect and enhance cultural landscapes is particularly crucial in remote, mountainous, inaccessible and isolated settlements which experience serious viability problems. In fact, it is particularly disconcerting that many culturally significant settlements are declining, abandoned by their permanent residents and ruined because of their geographical isolation, poor infrastructure, difficult living conditions and limited connectivity, that leaves them on the margins of a centralized development model based on economies of scale. At best, such settlements have only a short life span each year, that relies almost exclusively on tourism and the holiday of locals who retain nostalgia for their place of origin, despite their particular advantages, such as an important geopolitical position, rich natural and cultural resources and proximity to areas of particular natural beauty, characteristics that once allowed these settlements to play a role in social development and to be, today, part of our historical heritage.

Such «disadvantaged» settlements in Greece are located mainly in the northern borders, the mountainous hinterland, the steep shores and the small islands of the Aegean. The «disadvantage» they present today, however, is a recent phenomenon. Most of the settlements a century or two ago, experienced prosperity, due to their participation in economic networks that extended outside the geographical area of modern Greece and were based mainly on agricultural, manufacturing and commercial activities. During the Ottoman Empire Rule, for example, the difficult access was an advantage. The mountainous areas were inaccessible to the conquerors and for this reason they were places of strategic character and geopolitical importance, «arks, nurseries and clusters of freedom, autonomy, resistance, conservation of conscience, preservation and development of local cultures and life in general and with the utmost respect for the natural environment, with friendly methods and techniques of agriculture, use and management of soils» (Rokkos, 2004) [7].

The objectives of sustainable development are the reassurance of social solidarity and quality of life and the transformation of inaccessible places into attractive destinations for permanent settlement of young people and entrepreneurs. The enhancement and promotion of a distinct place identity and uniqueness, the protection of natural, historical, architectural, cultural heritage, tradition, (formal/recorded and informal/oral), the introduction of financial incentives and investments, the sustainment and strengthening of local activities and production, the modernization of infrastructure, the improvement of transport and road connections together with urban planning strategies that will form a dynamic place image

\footnotetext{
${ }^{* *}$ The European program Creative Europe, for example, states the need to support the cultural sector that is considered to be at risk from an environmental and human point of view.

${ }^{\dagger}$ European Landscape Convention, Florence, 20 October 2000. https://www.coe.int/en/web/conventions/full-list//conventions/rms/0900001680080621.
} 
and will improve the existing one, can contribute to this. Understanding, highlighting and protecting the cultural landscape can contribute to the development of such strategies by strengthening the identity and commitment of local communities to a development model that does not ignore modern needs but respects local resources.

Cultural landscape management policies can be summarized into two categories, internal and external. A combination of both is necessary in order to achieve sustainable development of inaccessible settlements.

Internal management policies aim to raise the awareness of residents and those directly affected in a settlement. They promote the acquaintance, participation and development of emotions, feelings, knowledge and the construction of place identity. They are based on the fact that when a person feels that he/she is a part of something, he/she is more likely to take action in order to protect, develop and promote it. According to geographer E. Relph (1976), an ideal condition for achieving a deep relationship between person and place is the development of emotional bonds and the rendering of meanings. Equally important, however, is the feeling of belonging that comes from the deep identification with a place through imagination and art, that is, when the experience of acquaintance of a person with a place is achieved through artistic means, such as literature, music, cinema, painting [8]. Philosopher Susan Langer states that in artistic creation meanings become more directly understood because no thoughts mediate to the communication [9].

For this reason, we believe that mapping can play an important role not only in the exploration and understanding of the cultural landscape by experts, but also in its semantic, emotional and experiential appropriation by the public and, above all, by local communities. In order to achieve effective management policies of cultural landscapes it is essential to adopt participatory mapping approaches and produce collective, imprints. Moreover, the visualization of the imprint with artistic means, may make it more attractive to the public.

External management policies concern the promotion of a settlement in a wider geographical context through its integration in various networks (geopolitical, conceptual, of actions, etc.), the promotion of its specific features, the attraction of people and capital and the development of entrepreneurship, creativity and liaison with central places. The large scale offers greater dynamics and increases the sustainability of settlements. Creating a strong and legible place identity based on a thorough, pluralistic, inclusive understanding of the place's cultural heritage is therefore important. It allows a settlement to have a uniqueness, a specific role to the operation of a wider network based on specializations and differentiations. Place identity is neither a management tool nor an exportable product but the (tangible and intangible) expression of the collective memory and sense of continuity shared by members of a community. Therefore, it should be built through bottom-up procedures with the cooperation and dialogue of local stakeholders. It should combine external with internal management policies. The ultimate goal is to create «beloved places» with strong ties to the inhabitants, that is, «topophilia» (Bachelard, 1958) [10] and at the same time to create «attractive destinations» for visitors or future settlers who will want to get to know the settlements, connect with their physical, human-made and social features and act beneficially and responsibly for them [11].

\section{Materials and methods}

\subsection{Revolutionary Palimpsest: a research project for the enhancement and promotion of the settlements of the Greek Revolution}

The fall of Constantinople in 1453 marked the consolidation of Ottoman rule in Asia Minor and allowed its expansion into the Balkans, the Greek peninsula and the Aegean islands. In 1821 and after many local uprisings, the Greeks declared a revolution that led to the creation 
of an independent Greek state in 1828, triggering the processes of ethnogenesis in the Balkan Peninsula. As Eric Hobsbawm points out [12], the revolution of 1821 was the first of the $19^{\text {th }}$ century revolutions to succeed. This success is due to its genuine «popular» character (with the mobilization of peasants and rural robbers together with city and diaspora merchants) which «became the inspiration for international liberalism» in an era of conservatism in Europe. It provoked a broad stream of support for the Greeks' war of independence amid the favorable diplomatic environment shaped by international competition for control of the eastern Mediterranean basin.

As a founding act of modern Greek history, the revolution of 1821 occupies a central place in the narratives that have since fuelled the Greeks' national consciousness, the "official» history, the collective memory and the local traditions. This year's $200^{\text {th }}$ anniversary of the proclamation of the revolution provided an opportunity to reflect on this heritage.

This paper draws on an ongoing research project that seeks to contribute to this field of reflection by examining the spatial expressions of this heritage, the material and intangible traces left by the events of the revolution in various places in Greece. The research project «Revolutionary Palimpsest. The visualization of the network of the distinct settlements in the space-time spectrum of the Greek Revolution» (2020-2022), aims to elevate the cultural landscapes of «revolutionary settlements» as a means for their sustainable development. It is funded by the Hellenic Foundation for Research and Innovation (H.F.R.I.) in the framework of the action «Science and Society» «200 years since the Greek Revolution» - Host Institution: School of Architecture, National Technical University of Athens, Collaborating Institutions: University of Thessaly, Technical University of Crete and University of West Attica, Project Coordinator: E. Tsakiri, Scientific Supervisor: H. Haniotou.

In the above project, a combination of scientific research and artistic expression is used in order to create artistic visualizations of Greek settlements related to the Revolution of ' 21 highlighting both their specific role in the revolutionary process (based on their particular geographical, social and cultural features), and the mnemonic traces of that process enshrined in their structure, landscape and tradition, as elements of their identity. By presenting these visualizations to the general public, on the occasion of the $200^{\text {th }}$ anniversary (1821-2021), the project aims to strengthen their positive image as living (not marginalized) parts of the Greek territory, an aim that reflects the objective of the development of Greek periphery with the contribution of culture and in particular with tactics that highlight the identity and uniqueness of places.

The Greek Revolution, or the Greek War of Independence (as it is commonly referred to) and the liberation of the Greeks from the Ottoman rule took place in the early $19^{\text {th }}$ century with a symbolic official start date of March 25, 1821. The $19^{\text {th }}$ century and especially the years of transition from Ottoman rule to Rebirth and formation of the Modern Greek State is an important historical period for Greece with an impact on the development of the economy, society, culture and politics which ultimately determined its contemporary image. The importance of the Greek Revolution is not limited to the geographical borders of Greece. It is an event integrated in the wider network of claims and dissemination of revolutionary ideas and actions in Europe which is active in direct connection with the Enlightenment and the French Revolution, in which Greek intellectuals and artists participated with approaches that shaped the modern European city and highlighted modern European culture. It is important to point out that many revolutionary settlements within the current geographical territory of Greece participated in the $19^{\text {th }}$ century in networks that extended throughout Europe through commercial, economic, socio-political, philosophical, and artistic relations, that determined the role these settlements had in the Greek Revolution.

The enhancement and promotion of the cultural landscapes of settlements through their correlation with the Greek Revolution is an option that combines two advantages: a) connecting all settlements with a common and strong idea of local, national and European scope that will function as unifying element and will construct a network of places which as a whole will refer 
to a supra-local scale with mutual benefit for all; and b) the formation of a distinct and specific cultural identity with diverse spatial and temporal manifestations, similarities and differences with Greek Revolution as a point of reference common for all settlements, a starting point that may trigger a wider mining into their cultural and historical background.

\subsection{Revolutionary Palimpsests: aims and objectives}

For the purposes of the research project, the researchers selected settlements, isolated or parts of wider networks, in the Greek territory with a historically documented contribution to the revolution and the formation of the Greek identity. The investigation starts from the present and moves towards the past as an «archaeological excavation» in the collective memory of the revolutionary settlements which are mapped and depicted as «palimpsests». A palimpsest is a papyrus, parchment or generally a manuscript used one or more times after earlier writing has been erased, a surface where the original text is being scraped in order to write on top of it something new, a material that consists of diverse layers or aspects apparent beneath the surface. The term is used in various scientific fields in order to determine the layered structure of a phenomenon. Architects and urban planners and designers attribute it to settlements, as they consist of layers of cultures that have left their mark and shape their contemporary image and reality (Bedard 1994, Huyssen 2003) [13, 14]. In this sense the palimpsest expresses the cultural interweaving, the succession of periods of prosperity and decline, seen as coatings of conquerors. Archaeologists use the term to describe the excavations for settlements that have experienced many periods of inhabitancy. In excavations all cultures that existed in a place leave their traces in layers of soil (a well-known example is the nine cities of the Homeric Troy). Palimpsest and multi-layered structures also reflect the modern scientific ascertainment that cities and settlements in general are characterized by complexity (Batty \& Longley 1994) [15] i.e., organized in parallel spatio-temporal and perceptual layers. The term «revolutionary palimpsests» in our research project describes our methodology of mapping and visualizing revolutionary settlements through horizontal sections in time (a path towards the past with the present as the reference point) as a means to investigate and illustrate the influence they had in the revolution and in the formation of contemporary Greece.

The investigated settlements are the matrices, the nuclei, the cradles of the Greek revolution. As «revolutionary» are defined the settlements that functioned as the administrative centres of Greece at that time, the places of battles that were decisive for the outcome of the revolution. They are also the birthplaces of heroes, the spiritual and economic metropoles of Hellenism, the urban centres with a large population and trade connections in Europe and the world beyond the Ottoman Empire, the nuclei that kept the Greek spirit and culture alive, the places of significant architectural heritage, of unique cultural landscapes and the small, inaccessible, mountainous and island settlements that were in the 19th century the epicentres of revolutionary action.

It is a fact that in every place, region and «corner» of Greece the revolutionary spirit was simmering therefore the choice of representative settlements for the research project was particularly difficult. For this reason, together with the historical documentation, additional criteria were set: geographical location, accessibility, level of development and size. Regional, small-scale, inaccessible settlements, individual or integrated into wider networks or sets, settlements that face economic decline and isolation and are today deserted, small villages, with only a few inhabitants but very important in terms of architectural and cultural heritage, places located in landscapes of significant natural beauty, presenting features that unfortunately remain untapped, had special priority in the selection. Their promotion aims to: a) make the settlements known to the general public, the visitors and the travellers; b) activate the inhabitants who, knowing their history and the struggles of their ancestors, will be connected with the place, will appreciate it, will feel proud and will continue the struggle for its preservation and promotion; 
c) connect the settlements with networks with a common historical identity in order to create a supra-local scale for their development, d) promote, highlight and activate inherent dynamics; e) highlight the connection of these settlements with elements of Greece's wider cultural heritage and identity, forming a common ground that will start from, but will not be limited to, the historical context of the Greek War of Independence.

\subsection{Revolutionary Palimpsests: methodology}

The methodology adopted by the research project combines scientific and artistic means. The documentary character of «traditional» practices of quantitative urban analysis is interlaced with the polysemy and the expressive freedom of artistic mapping and data visualization approaches. The dual scientific and artistic procedure, which juxtaposes objectivity and subjectivity, reflects the anthropocentric, phenomenological approach that has been gradually formed after the mid- $20^{\text {th }}$ century and was adopted in humanistic, social and spatial sciences. Creative geography, for example, begins to study artworks, such as veduta and landscape painting (Hawkins, 2013) [16]. Cartographic approaches, such as psychogeography, mental, radical, creative, experimental and critical mapping, move away from the purely quantitative and objective methods of traditional and academic cartography that were connected with centralized organizations, power and control of space [17]. Critical cartography in particular encourages interdisciplinarity, combinations of data and methods, such as practices from urban theory and visual arts, a mix of perceptions and facts, of quantitative and qualitative data, of personal views and substantiated analysis. The object of mapping is the ontological character of the social reality, the reality of the senses and experiences. The critical approaches combine quantitative with qualitative methods, explanation with interpretation, include elements of history, culture, social structures, human action and interaction and address the new, complex reality that consists of layers and interdependent processes (Archer, et al., 2016) [18]. This way, mapping adopts a dual, scientific and artistic character. Scientific methods regulate the high degree of artistic subjectivity and vice versa. The practices allow the transmission of both information and aesthetics, produce visualizations that include references to their creation procedure, artworks that address a non-specialized public, that aim to attract, to impress and at the same time to inform. Contemporary maps are evaluated not only on the basis of the data they represent, but also on the basis of their dynamics in communication [19].

The research project involves architects and artists, teachers and students, with two main roles: «cartographers» and «artists». The cartographers' task is to investigate the revolutionary settlements through urban analysis and mapping tools, and the artists have to represent them through artistic visual means. The overall aim is to disseminate the knowledge acquired for the settlements in the research process by an exhibition of their cartographic artistic visualizations. The exhibition is planned in order to make know the places, their importance in the outcome of the Greek Revolution and in the formation of the history and culture of modern Greece. It aims also to unveil to the public their problems and perspectives and to show in an alternative and emotional manner the inequalities between center and periphery. More importantly, it aims to emphasize the paradox of fame, glory and heroism that were followed by an unfair negligence and decline, to raise awareness and open a channel of communication with stakeholders and power institutions. The visual art exhibition will take place in September 2021 in Athens. It will present the visualizations of revolutionary settlements in a non-conventional way, in which the artworks will impose themselves as symbolic riddles. The exhibition will include the mapping processes and will highlight the construction of the visualizations, which is a suggestion for an interdisciplinary, contemporary, open and inclusive process of exploring cultural landscapes. Some artworks will also have an interactive role and the visitors will be invited to participate, reinforcing thereby the feeling that they are personally concerned and participating in the process. 
Specifically, the visitors will have the opportunity to record their views and feelings about the visualizations of the settlements on a mapping background, and they will have access through QR-codes to additional information about the revolutionary settlements in the database of the research project's website. In this way the exhibition will become an open window to a world of perspective and exploration. It should be noted here that more than 200 different settlements throughout the geographical territory of Greece have already been explored, mapped and visualized in various ways, so the visitors of the exhibition will most likely come from and be related to some of these places. This is expected to activate identities and emotions.

The investigation of the revolutionary settlements combines principles of urban theory, urban analysis and mapping practices (psychogeography, mental mapping, radical, creative, experimental, critical cartography). The findings are organized in groups and form the conceptual background on which the artists produce visualizations of the settlements. The expressive means that they use emanate from the disciplines of architecture, cartography and painting while the concept of «palimpsest» is a necessary precondition for all artists, both in the analysis and the composition phases. The tasks are undertaken by two groups: The «cartographers», an 18-member team of researchers specialized in urban planning, urban design, urban history, urban geography, philosophy, aesthetics, culture, sociology (8 academics and 2 postdoctoral researchers) that support the interdisciplinary approach of the research, have chosen the revolutionary settlements based on historical and geographical criteria and carry out their mapping according to the methodological principles of the project (explained below). The «visual artists» team a 10-member team specialized in political science, archaeology, philology, theatrology, scenography and arts (7 academics, a postdoctoral and a doctoral student) in collaboration with 5 artists will visualize each a revolutionary settlement or a network of revolutionary settlements. The 18 researchers also counselled students, undergraduates and postgraduates that participated in three university classes and an interdisciplinary workshop that took place last year. A total of over 300 students throughout Greece participated, coming from architecture schools - (the Host Institution and the Collaborating Institutions of the research project). There were also some students from Europe that attended the classes through the Erasmus program. The participants produced about 1000 different visualizations for about 150 revolutionary settlements, which reflect how young people see and feel today about the revolution and its spatial manifestation, how they evaluate, judge and interpret it. All of these constitute a crowd-mapping project, a bottom-up mapping process whose artworks (connected with the settlements) shape the overall map of the revolutionary heritage that will be presented in the exhibition.

In the mapping process, the revolutionary settlements are treated by researchers as «nodes», as «palimpsests» and as «condensers» and are investigated respectively in three ways: a) spatially as networks of relations; b) chronologically as successions of events, impressions and traces of the past that survive in the present; and c) analytically and in detail by delving into important elements of their cultural identity. Researchers collect contemporary historical studies and explore the settlements with reference to their geographical location and the facts that evidence their evolution in the $21^{\text {st }}$ century, emphasizing the importance that, in their perception, the characteristics of the settlements had for this evolution (their physical morphology, their economy and social organization, their spatial organization and interconnection, their cultural composition, etc.). Discussing the sequence of events, they develop a way of visualizing, contributing both to a mapping and a dating, in which their ideas about the local peculiarities that make them or are made meaningful by them are incorporated. In addition, they collect informative/illustrative/ narrative material from these settlements (paintings, literary texts, folk songs, cultural elements such as costumes, weapons, flags, etc.), insisting on both the way the settlement contributed to the revolutionary process and the way it bears today its material and intangible traces which are 
intertwined with the impressions, the qualities, the values, the meanings that have been attributed to it since then and have contributed to the formation of its contemporary image.

The next phase is to create artistic visualizations based on the mapping. In some cases, mapping and artistic visualization cannot be separated and the researchers use the mapping itself as the background of their visual artwork. As stated above, the visualization of the revolutionary settlements has a necessary precondition: the placing of the findings of the mapping on superimposed levels and the creation of works which will function as «visual palimpsests». The organization of diverse data in groups and layers enables the inclusion of a multifarious content in the visualization and facilitates its management. Moreover, the multi-layered structure expresses the simultaneous action, interaction and interweaving of various factors, spatiotemporal perceptions, a property that in the critical cartographic approach expresses the description of modern reality as complex, consisting of layers and interdependencies. The entanglement of the various elements in levels and their simultaneous view creates varied relations between them and a «visual complexity» that expresses in the visual environment the description of settlements as systems of organized complexity.

Both mapping and visualization (they are not separated, but are instrumentally organized into two distinct phases) follow specific methodological principles, common to all researchers, «cartographers» and «artists». They are defined by a framework of principles and procedures (Poli-Plex-Icon mechanism) which employs conceptual and morphological elements from the fields of architecture, cartography and painting and focuses on sociospatial complexities. Special mapping reports are used for the collection of data from the revolutionary settlements in an organizational form that consists of groups and sub-groups as listed in the table below. The «cartographers» can supplement the reports with keywords or free text and they can enrich them with their own observations, depending on the specific case of the settlement they are investigating. The findings are then made available to the «visual artists», who visualize and turn the mapping of a settlement into a visual palimpsest. The following three tables illustrate the steps of the process according to the Poli-Plex-Icon mechanism (Tsakiri, 2018, 2020) [20, 21]:

Table 1. Poli-Plex-Icon Mapping Phase.

\begin{tabular}{|l|l|l|}
\hline \multicolumn{2}{|c|}{ MAPPING } \\
\hline $\begin{array}{l}\text { STEP 1: collection of various } \\
\text { mapping data }\end{array}$ & $\begin{array}{l}\text { Sources may include: in situ mapping, photos, videos, sketches, books, booklets, } \\
\text { journals, travel guides, records of spoken traditions, legends, customs, tales, personal } \\
\text { stories, interviews with inhabitants, etc. }\end{array}$ \\
\hline $\begin{array}{l}\text { STEP 2: arrangement of } \\
\text { findings into groups } \\
\text { (horizontal organization) }\end{array}$ & Findings organized into groups and sub-groups as follows: \\
\cline { 2 - 3 } & Natural Environment & topography | ambience, climate \\
\cline { 2 - 3 } & Built Environment & $\begin{array}{l}\text { materials, colors | plan, spatial organization, urban grid | } \\
\text { morphology, typology, geometry, morphological pattern } \\
\text { repetition }\end{array}$ \\
\cline { 2 - 3 } & Perception \& Experience & $\begin{array}{l}\text { mental mapping I characteristic city view | multisensory } \\
\text { perception }\end{array}$ \\
\cline { 2 - 3 } & $\begin{array}{l}\text { Actions, Functions, } \\
\text { Networks, People }\end{array}$ & $\begin{array}{l}\text { nodes and movement channels | spatial distribution of } \\
\text { functions \& actions) | social and anthropological elements }\end{array}$ \\
\cline { 2 - 3 } & History \& Ideology & $\begin{array}{l}\text { emotional impression \& characterization | Semantic places } \\
\text { I concepts reflected in space | symbols I genius Loci }\end{array}$ \\
\hline $\begin{array}{l}\text { STEP 3: correlation of } \\
\text { findings, construction of } \\
\text { narratives }\end{array}$ & $\begin{array}{l}\text { Findings are correlated with the concepts and / or events of the Greek Revolution and } \\
\text { its evolution to build concrete narratives that will be used in the visualization process. }\end{array}$ \\
\hline $\begin{array}{l}\text { STEP 4: semiotic } \\
\text { elaboration of findings } \\
\text { (vertical organization) }\end{array}$ & $\begin{array}{l}\text { Findings are correlated with affiliated concepts, ideas, analogies, and associations, to } \\
\text { deepen the narratives. }\end{array}$ \\
\hline
\end{tabular}


Table 2. Poli-Plex-Icon Visualization Phase.

\begin{tabular}{|l|l|}
\hline \multicolumn{2}{|c|}{ VISUALIZATION } \\
\hline $\begin{array}{l}\text { STEP 5: visual elaboration of } \\
\text { findings }\end{array}$ & Findings are correlated with visual elements, shapes, motives, colors. \\
\hline $\begin{array}{l}\text { STEP 6: placing of visual } \\
\text { elements into layers }\end{array}$ & $\begin{array}{l}\text { Elements are placed on transparent layers that facilitate visual mingling. The layers aim } \\
\text { to organize the narratives, while, at the same time, transparency will produce } \\
\text { interrelations and mingling. }\end{array}$ \\
\hline $\begin{array}{l}\text { STEP 7: layer } \\
\text { superimposition and } \\
\text { coloring }\end{array}$ & $\begin{array}{l}\text { Layer superimposition results to visual complexity. The artist will subsequently hierarch } \\
\text { the narratives by accentuate shapes and motives. }\end{array}$ \\
\hline
\end{tabular}

Table 3. Poli-Plex-Icon in a diagram of 7 steps (E. Tsakiri).

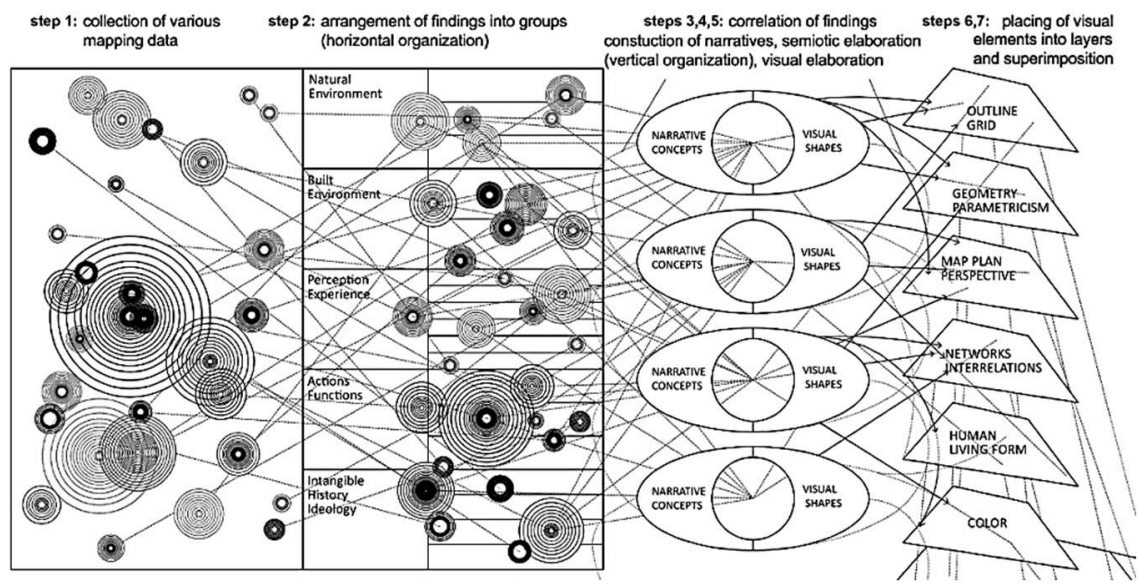

\section{Results and discussion}

\subsection{Souli and Mani: the glorious revolutionary settlements}

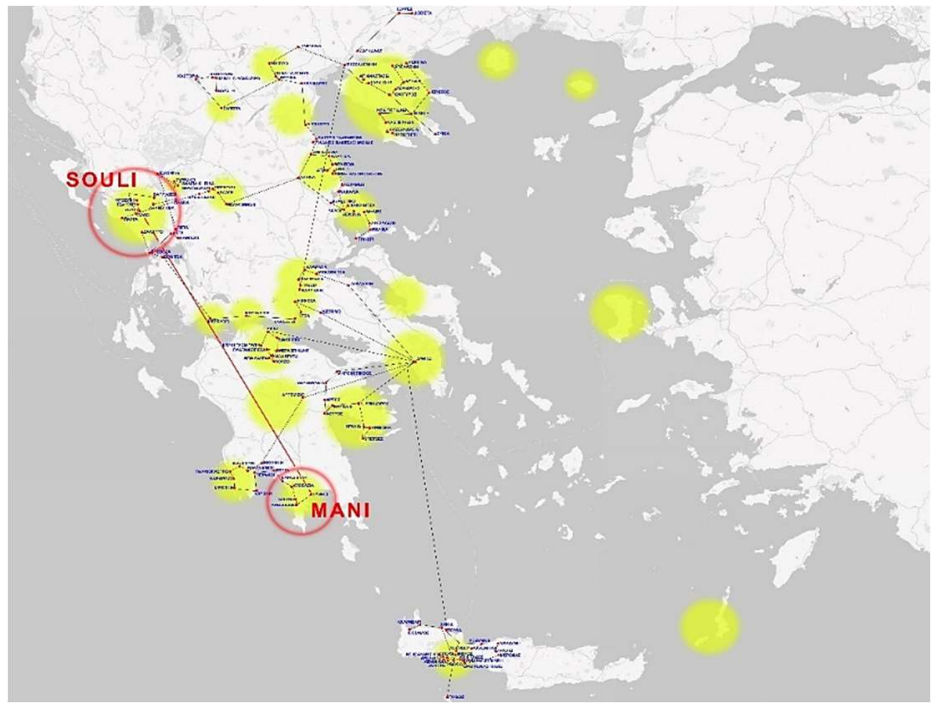

Fig. 1. Networks of revolutionary settlements in Greece. Highlighted are the Souli and Mani areas and their villages (E. Tsakiri). 


\subsubsection{A small contribution for Souli}

As it is mentioned above, the historic origin of the term «palimpsest» is correlated to a sequence of superimposed inscriptions on an ancient parchment; the previously written texts being effaced, scrapped, in order to offer the possibility of re-use. It would be possible however to read partly apparent parts of the previous inscriptions under the most recent writing. Lesser known is the figurative use of the term, as in the theoretical context of «transtexuality», defined by Gérard Genette as the «textual transcendence of the text [...] that sets the text in relationship, whether obvious or concealed, with other (previous) texts» (Genette, 1982/Moraitis \& Filippidis, 1993) [22, 23]. Thus, according to an analogous figurative approach, we may refer to the «revolutionary palimpsests» as place formations created on sequential layers over previous «cultural landscapes» closely associated to nodal places of the 1821 Hellenic Revolution. According to another figurative approach, we may speak of «ideological palimpsests», a sequence of ideological influences, cultural influences in general or political influences in particular which had produced the ideas of the Hellenic Revolution in accordance to the intellectual and philosophical movement of the «Enlightment», the «siècle des Lumières» that dominated the world of ideas in Europe during the $17^{\text {th }}$ and $18^{\text {th }}$ centuries. Nevertheless, we may also present the cultural and political current of the Enlightment in its historical reference to the democratic «classical» Hellenic antiquity; the latter being the initial referential paradigm for the neoteric demand for independence and political equality.

In this sequence of political associations, we may also indicate the ideological importance of the «Hellenic Enlightment» as produced principally in the Ottoman and European urban centers where important Hellenic communities lived. We may also indicate the importance of the active, militant Hellenic resistance in Ottoman Greece previous to 1821. We may present them as important examples that nourished the Hellenic demand for freedom and gave birth to the final 1821 revolutionary act. Among those examples, we may focus on the flourishing Hellenic urban communities, the cities of the geographical territory of Epirus in northwest Greece; being highly influenced by the current of Enlightment. We may also focus on the heroic armed resistance of the inhabitants of the villages of Souli, also in Epirus, in its mountainous part. Both previous paradigms may be judged as highly influential for the years of the revolutionary 1821 period, as well as for the didactics of freedom for the generations of Greeks to come and, moreover, for neoteric Western political history in general.

It was to the mountainous area of Souli and the territory of Epirus in general that a part of our project was dedicated.

The area of Souli, in the part of Epirus known as Thesprotia, is located in a valley of high altitude formed by the Paramythia and Thesprotian mountains. Its location that includes valleys, gorges, steep ridges and mountain peaks, rocky and wooded areas, could be described as a natural fortress. It still has the historical fortune to be at the vicinity of river Acheron, the river that according to the ancient Greek mythology was leading to the underworld; its name haunted for thousands of years the dark fantasies of the ancient and modern Western thought.

The geomorphology that characterizes the area led from the $16^{\text {th }}$ century on to periodic relocations of residents from neighboring villages that were trying to avoid attacks and slavery. The Souliotes occupy the area since $800 \mathrm{BC}$. And, according to some historians they were descending from the ancient tribe of Sells, inhabiting the mountainous areas of Epirus. According to local scholars, the Souli Confederation included 129 villages in the prefectures of Ioannina, Thesprotia and Preveza and had a population of 12,000 inhabitants. The Souli Confederation was distinguished for the special way of governing and organizing the commons, which made it a powerful force and an invincible target for the Ottomans. It formed a peculiar community with a strong internal organization and an equally strong sense of independence, which explains the historically prolonged conditions of their independent living. In the $18^{\text {th }}$ century, the Ottomans heavily attacked and were repulsed by Souli. In 
1803, Ali Pasha, the Ottoman governor of Epirus of Albanian origin, began his third attempt to exterminate Souliotes and after three years of conflict he forced them to capitulate. The main condition of the agreement for the Souliotes was to evacuate the villages while maintaining their armament. On December 16, they split into three phalanxes and left their land. The first group managed to reach Parga, on the coast of Ionian Sea, and passed safely to the island of Corfu. The second group arrived to the mountainous territory of Zaloggo and, being defeated by the Ali Pasha's troupes, had to choose between slavery or death. It was there that sixty Souliotes women refused to surrender. They preferred to die. Dancing and singing their farewell to life they threw themselves, one by one together with their children, down from the cliffs of Zaloggo. Their act was inscribed in history as a heroic self-sacrifice, as a paradigmatic act of courage and determination, worthy to be commemorated and depicted for the generations to come. The third group finally arrived to the monastery of Seltso. It was besieged and defeated; there again many of the fugitives preferred suicide than slavery. After 1820 , the Souliotes that survived return to their villages and decided to ally with their enemy, Ali Pasha, in order to help him against the central Ottoman governance of Sultan. Unfortunately for them Ali Pasha was defeated and killed; Souliotes quitted again their villages and fervently participated to the Hellenic 1821 Revolution.

To this heroic resistance and sacrifice were dedicated two of the works created in the course of the research and artistic mapping of «Revolutionary Palimpsests». The first one presented the history of Souli as a sequence of events, proving its inhabitants' volition for independence. Moreover, this first approach tried to depict the impact of those historic events, of the revolutionary allure of Souli, to the political imaginary of the following generations, in Greece or at a larger scale of influence, on the European and international level of reference. It was the romantic British poet and philhellene George Gordon Lord Byron who dedicated in his poem Childe Harrold's Pilgrimage [Canto the Second, XLII, 370] his verses to Souli. «Dark Suli's rocks, and Pindus' inland peak», he wrote... and continued «Robed half in mist, bedew'd with snowy rills, /Array'd in many a dun and purple streak, «Arise; and, as the clouds along them break, /Disclose the dwelling of the mountaineer: /Here roams the wolf, the eagle whets his beak, /Birds, beasts of prey, and wilder men appear, /And gathering storms around convulse the closing year». Byron was expecting that after his arrival in Greece he could meet the famous Souliotis leader Marcos Botsaris and conjoin with him in favor of the Hellenic 1821 revolution. Unfortunately, Botsaris was killed before Byron's arrival in the Greek besieged city of Messolonghi. Did he feel a political correlation to the Souliotis heroic leader? He surely did, presenting a first layer of the international political palimpsest that continued to be developed for the next two centuries. In Paris, France, a station of the Parisian metro was given the name «Marco Botsaris Station» while in Strasbourg a city square was baptized after the revolutionary Souliotis.

The second work (Fig. 2) focused on the historic palimpsest of Souli and insisted on the women's position in the Souliotes' community. Suspicion for a woman's morals was enough to stone her. However, this extreme severity was not contradictory to the high esteem offered by the community to its female members. Women participated in the assemblies and were allowed to present their opinion. Furthermore, they were actively participating in the most decisive political expression of their independent mountainous society, the armed resistance against their enemies. In this context, this second research mapping tried to correlate the women's self-sacrifice at Zaloggo with other analogous events of extreme courage and determination that may be recorded in the course of the Hellenic 1821 Revolution or to its historic vicinity. Events during which besieged Greek women chose freedom through death for themselves and their children; throwing themselves in the foamy waters of Arapitsa river in Naoussa in 1822 during the siege and destruction of the city; committing suicide by falling into the sea on the island of Psara in 1824; or in Horigoskala in Peloponnese in 1826. 


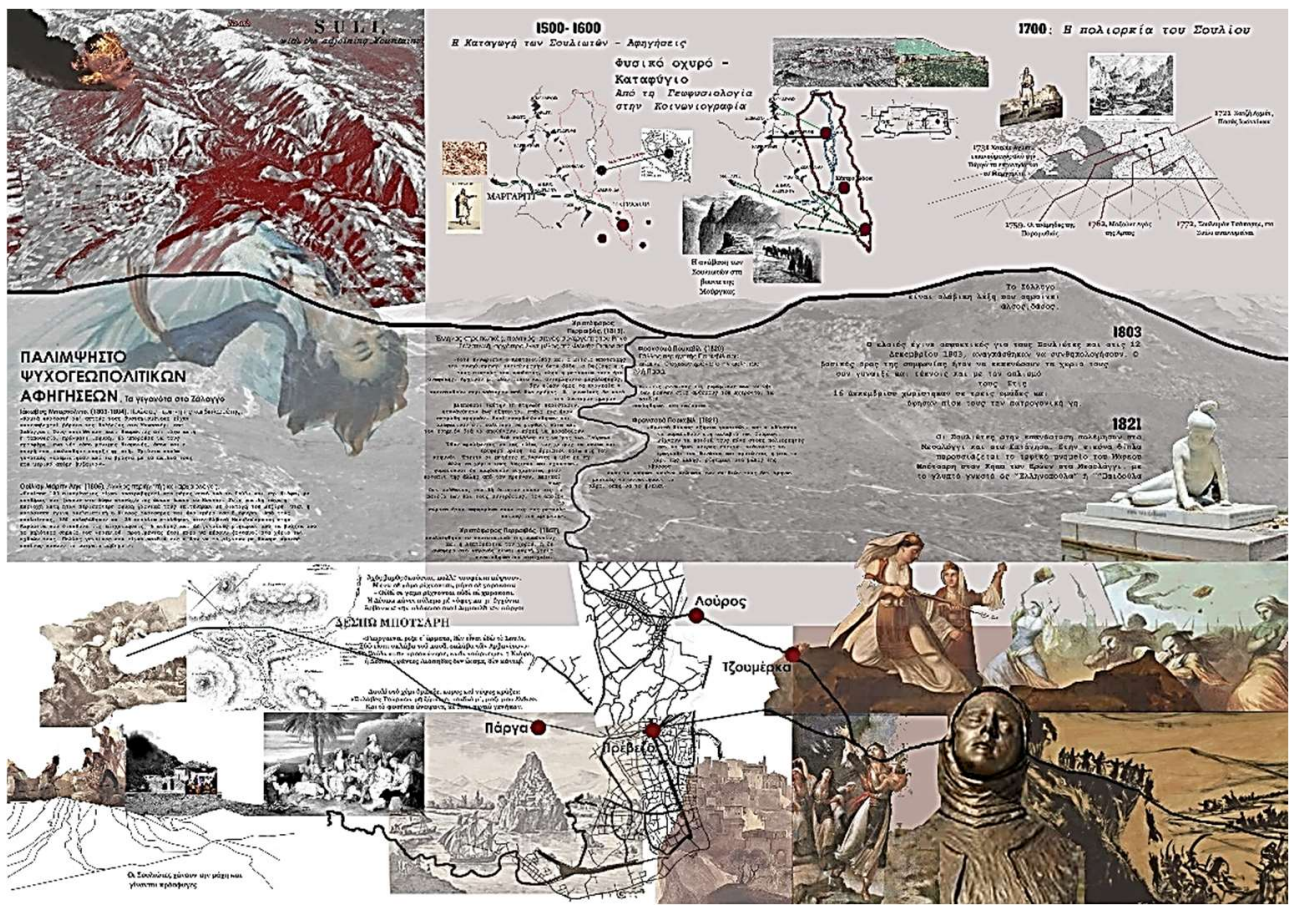

Fig. 2. The Souliotisses, the gender identity and the places of self-sacrifice by Theofani Papaioannou. Project coordinator: Konstantinos Moraitis.

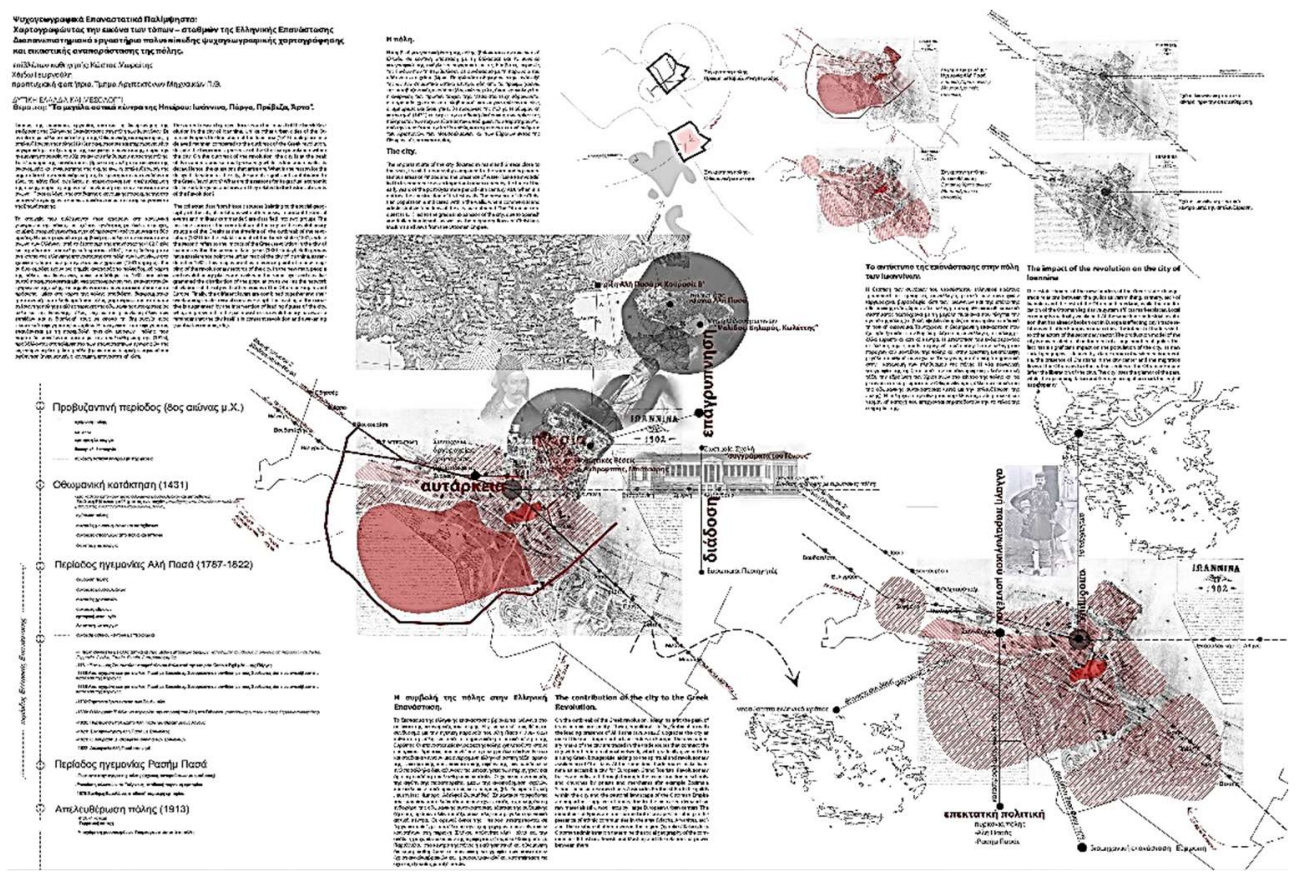

Fig. 3. The major urban centers of Epirus: Ioannina, Parga, Preveza, Arta by Chaido Georgouli. Project coordinator: Konstantinos Moraitis. 
A third narrative (Fig. 3), created in the course of the research and artistic mapping of the «Revolutionary Palimpsests», was dedicated to the impact of the cultural and political ideas, developed in the cities of Epirus during the late $18^{\text {th }}$ and early $19^{\text {th }}$ centuries, on the maturing of the revolutionary efforts. In the flourishing urban centers of the ottoman Epirus, Greek communities embraced the «enlightened» ideas and created the fertile cultural and political ground for the revolution to come.

Concluding our reference to Epirus in general and Souli in particular, we may present them as an exemplary opportunity for the application of the term «déterritorisation», as proposed by Gilles Deleuze Felix Guattari in their text on «Geophilosophy» [24]. Out of the natural place substratum, out of the "cultural landscape», cultural and political qualities emerge. Then, after their historic maturing, they come back. They fertilize the cultural landscape of their initial origin, in order to be correlated with it again, in order to be «reterriorised», («reterritorisées»), to be installed again in the material and the mnemonic, intangible identity of the place.

\subsection{The peculiar and insubordinate Mani, the villages, the towers, the people}

Approaching the area of Mani with the above mapping tools, our research project highlights the complex way in which collective memory records the events of the 1821 revolution in a pre-existing tradition of autonomy that is a constituent of local identity.

Working on historical sources, archival material, geographical and architectural information and elements of popular tradition, cartographic representations contribute to the detection of structural elements of this identity, not bypassing it as a «construction» (looking for what is «behind the myth») but understanding the myth that gives coherent meaning to social reality so as to mobilize social action. In the case of Mani, we must understand and depict the meaning that the local community gives to the traces of a moment of its past that seems to condense all historical time.

In the texts and data, we studied $\$$, the participation of the Mani people in the revolution of 1821 appears as a primary source of local pride and penetrates the popular tradition (as in that area the revolution was proclaimed) after the reconciliation of its leaders. That is, where the revolutionary oath was given, the flag of the revolution was raised and the call to the European governments for solidarity was written. The leader of Mani was appointed General of the Struggle for freedom.

The choice of area was wisely chosen. The semi-autonomous status, the fortified configuration and the inaccessibility of its territory were a deterrent to the immediate Ottoman intervention. The local ports provided the possibility of supplying or deploying the revolutionary forces. The traditional tendencies for autonomy of the area were a guarantee for the social acceptance of the revolutionary project. The discipline and readiness of the local army as well as the wealth of the area were a guarantee for the success and financing of the first military operations. For the needs of the research, we therefore had to insist on an approach through the geographical and social peculiarity of the place.

The historical area of Mani is located at the southern extremity of the Greek mainland. From the north it is bordered by the forested volume of the Taygetos mountains and occupies the Laconian peninsula that ends at Cape Tainaro, a sighting point of the entrance to the Aegean Sea since the Homeric years. It has a mountainous landscape with bare mountains, arid limestone soils, small plains and plateaus that produce high quality olive oil, rocky shores that alternate with protected coves and sandy beaches. The warm and dry climate, the intense

\footnotetext{
林et's not forget the definition of culture as a toolkit for social action [25] by Ann Swidler.

${ }_{\S}$ Mainly from Maniat researchers, associations and institutions and, very often, from Mani people of the Diaspora in Athens and abroad.
} 
sunshine and the strong winds form a familiar landscape, similar to the Aegean islands, with the stony soil and the bush vegetation.

It is an enclosed and inaccessible area, a natural fortress with a strategic advantage in controlling the sea routes. At the same time, it is a society that has maintained an ancient form of organization based on a loose confederation of armed rural clans and has always claimed its autonomy from all forms of government that have tried to impose themselves in the wider area. In such a society, the internal distribution of power depended on the number of men ready for war in each clan, and the management of internal rivalries with traditional rules of reconciliation was necessary in the face of external danger. Against the Ottoman administration, this society bloodily gained the status of semi-autonomous hegemony with significant tax exemptions, which allowed it a rare, for the time, demographic and economic development, despite the scarcity of natural resources. Thanks to their military organization, the people of Mani became sought after mercenaries in the wars in the eastern Mediterranean basin and engaged in shipping, piracy and smuggling. Women had a distinct role in the handicrafts (silk processing) and agriculture with the highest mission to give birth and raise the men (the «rifles») of the clan.

The ruins of ancient cities, sanctuaries, medieval castles and Byzantine churches that are today scattered in Mani are evidence of a lasting struggle for independence. The peculiar social organization is reflected in an extensive network of settlements composed of the fortified stone dwellings (tower houses) of powerful families in labyrinthine complexes with complicated communication and escape systems. The height of the tower houses marks the social status, wealth and power of the weapons of each clan represented by its «captain». This characteristically «Maniot» architecture is the product of an «economy of selfsufficiency» particularly ingenious in the integration of construction know-how, if we consider the number of conquerors who claimed control of the area (Romans, Byzantines, Franks, Venetians and Ottomans), but also the diachronic involvement of Mani in European competitions and transactions. The defensive nature of this architecture gives the measure of internal competition in a society dominated by rigid traditions, the sense of honor and the law of blood which is typically expressed in the Mani's vendetta.

These contradictions are also expressed in the value system of the local community that honors bravery and self-denial in favor of the Community good. The strong social control and the scarcity of natural resources created a strict and frugal culture with few moments of celebration. War operations, violent internal rivalries, the thirst for power, the game of danger and the familiarity with death made mourning an inherent element of Mani's culture, as seen in its famous lamentations, a kind of epic poetry improvised by women narrating dead's fate and virtues connected with the history of his family. We cannot, however, ignore the demand for dignity and self-sufficiency expressed in the strictness of this culture, the need for security expressed in its introversion and the irreconcilable demand for independence expressed in its violence.

If there is one place in Greece where the meaning of palimpsest finds its most eloquent form, this is Mani. A place that combines a strong identity with manifestations of extreme localism and a rich cultural tradition with strong conservative tendencies. A place of heartbreaking beauty and tragic memory, scattered by architectural forms that narrate wars but also triumphs (as the local community assumes its participation in the revolution). A landscape of hard stone, relentless sun, strong winds and thirsty land that narrates the collective struggle for survival (the culture itself) and overlooks the sea, the difficult road to freedom. A landscape that deifies every cistern and fountain, that records people, natural elements and ancient demons confronting in the secret mountain passes and the inhospitable shores. A landscape that reflects the spirit of independence that nurtured the revolutionary ideal, but also the civil conflicts.

Although having been the starting point and the rearguard of the revolution of 1821, Mani was found against the new Greek government's endeavour to modernize the administrative structures. Until the middle of the $20^{\text {th }}$ century, there were many uprisings, faced by 
repression and clientelism that intensified Mani's internal conflicts, culminating in the division of local society during the Greek civil war (1944-1949). All that led to the marginalization of the region and resulted in its economic and demographic decline.

In the 2011 census, the population of Mani was 20,285 inhabitants, while in the years of the revolution it was estimated at about 40,000. The post-war demographic decline of the entire Greek countryside was particularly evident in Mani, due to successive migratory outflows to neighboring cities, the USA, Piraeus and Germany. The reasons had to do with the scarce and unequal distribution of resources, with political persecutions and local rivalries often ended in a vendetta. The first recovery trends appear in the 1970s thanks to the development of tourism to which a policy of protection and preservation of local cultural resources contributed decisively. Today, out of a total of about 250 villages and small settlements, 98 are officially registered as traditional settlements, 800 stone towers are preserved (several of which have been restored and remain in operation), while in the jurisdiction of the archaeological offices are 7 medieval castles, over 1000 Byzantine and post-Byzantine churches and 10 sites with ancient Greek and Roman remains. The prosperous settlements are located mainly in the most fertile places and in the coastal zones such as the port of Gythio, Kardamili, Itilo and Areopolis, all connected with the revolution of 1821 and the Maniot families that participated in it.

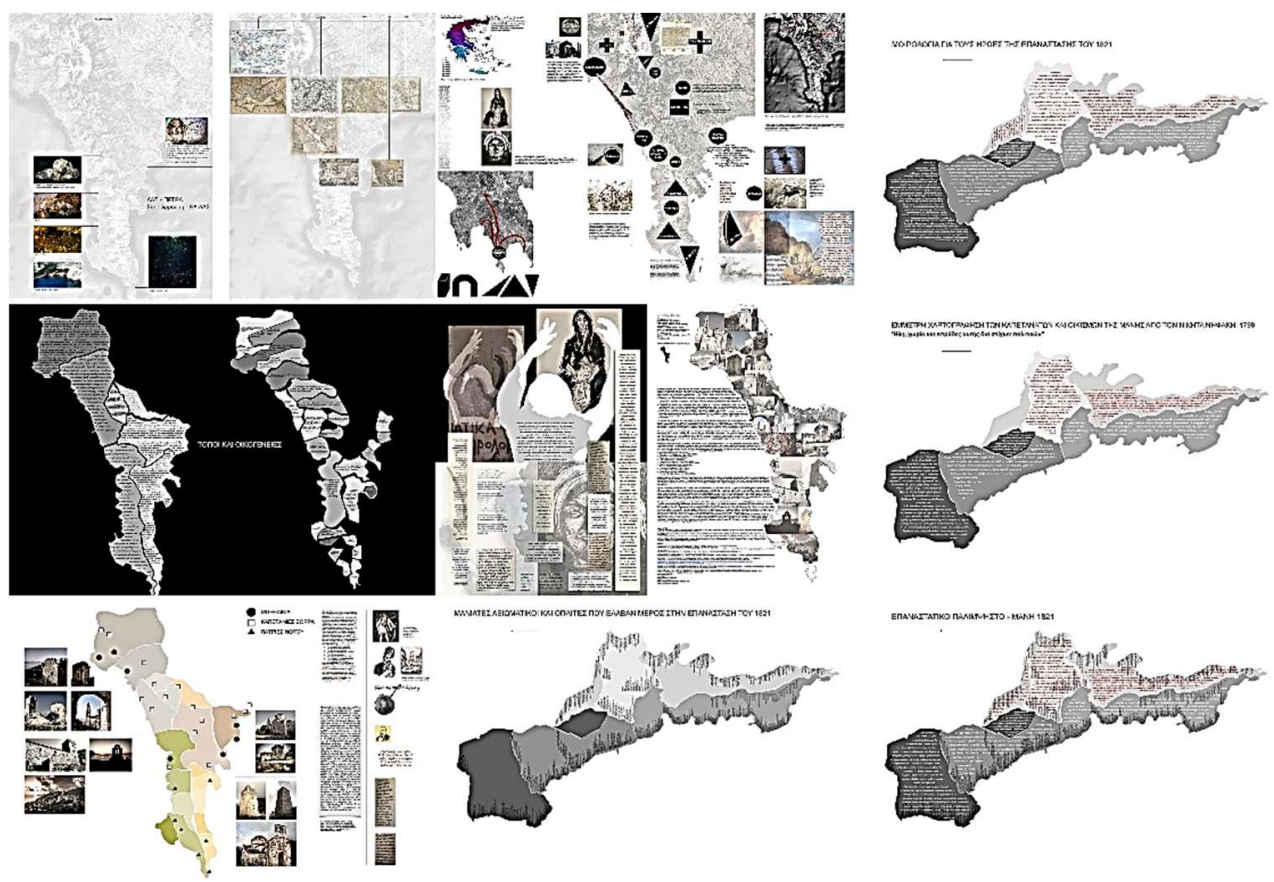

Fig. 4. The particularity of Mani region in the Greek war of independence by Katerina Stylianea. Project coordinator: Maria Markou.

Looking for the traces of the revolution «in form of a form» in the collective memory of the places, as required by the research project we present, the cartographic works concerning Mani impressively summarize the above observations, connecting the natural landscape and the terrain with the material and intangible elements of culture and the peculiarity of its social organization. One of these works (Fig. 4) ${ }^{* * *}$ focuses on the stories of Maniot families who

\footnotetext{
${ }^{* * * *}$ Katerina Stylianea, student of architecture with a degree in Political Science and Master of International Relations and Strategic Studies, on «The Mani peculiarity in independence».
} 
participated in the liberation struggle, connecting them with 96 fortified settlements of Mani and their special characteristics.

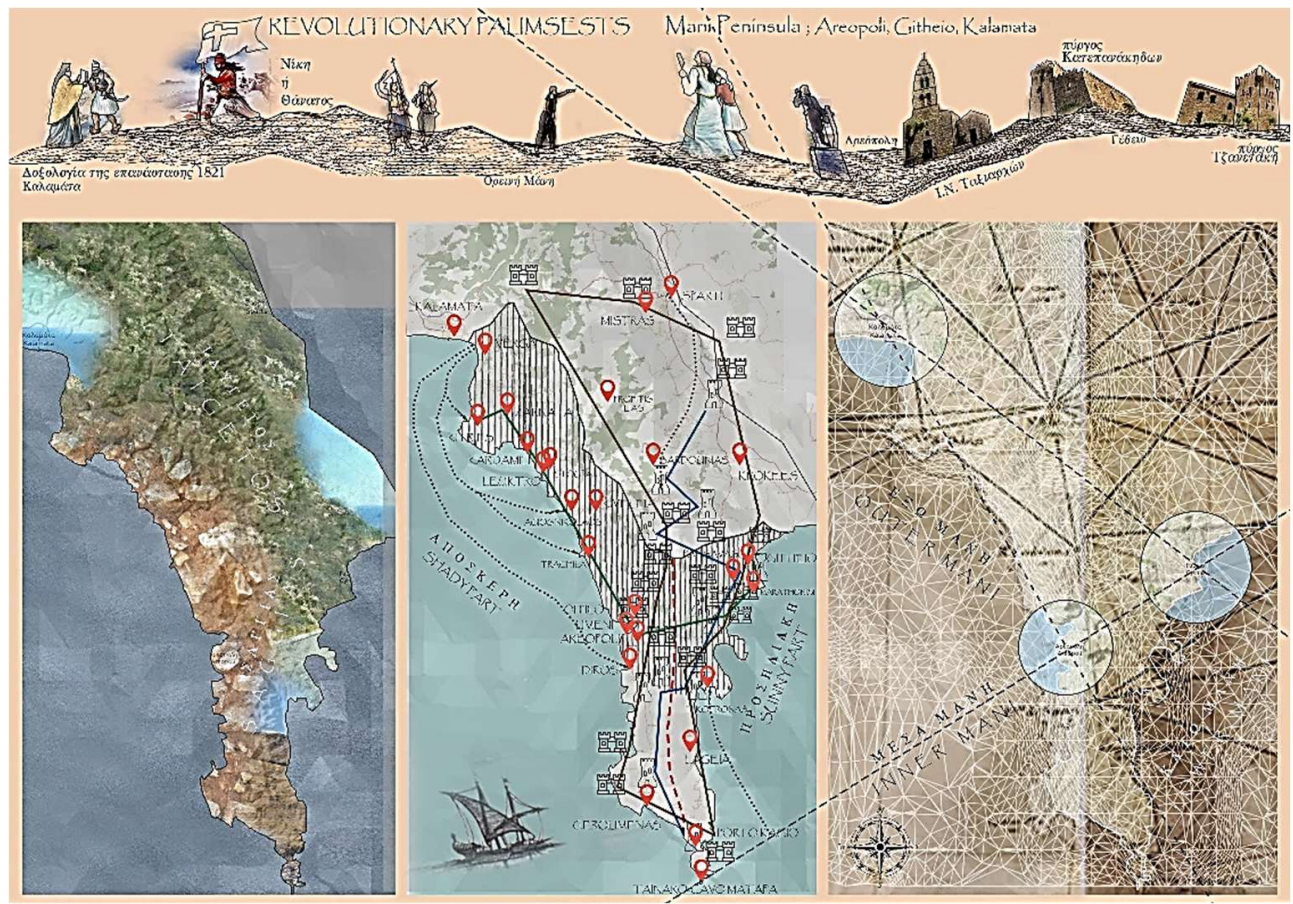

Fig. 5. The beginning of the revolution in Mani. Areopolis, Gythio, Kalamata by Evangelia Menia Dimitriou. Project coordinator: Maria Markou.

Another work is based on the rituals that commemorate the anniversaries of the events of the revolution in Mani, while a third one records the monuments associated with such events (Fig. 5).

With great freedom in the choice of approach, all the works compose a multifaceted rendering of the «palimpsest place» made of the overlapping mnemonic layers that give meaning to the space as an object of collective appropriation. The research project identifies the palimpsest place with the cultural landscape, supporting the need for its protection and study. It is known that this contributes to the attractiveness of a place. But local development is not just about attractiveness. It has to do with the living bond that any society maintains with an internalized environment full of meaning. This is the bond we are trying to approach.

\section{Conclusions}

The research work we present starts from the position that architecture is a socio-technical construction as is the cultural landscape which is inextricably linked to the architecture of a residential place and has a dual nature, natural and artificial, material and intangible as, in the collective imaginary of a society, its tangible characteristics refer to the culture produced by the interaction of human and space. The cultural landscape includes elements of our cultural heritage but it is also itself an element of this heritage. This position is currently adopted by important international and European policy texts on place, landscape, architecture and cultural heritage; texts that argue that the protection and promotion of the cultural landscape is particularly important for the sustainable development of a place.

The research project wants to contribute to the enhancement of the cultural landscape through a mapping method that artistically elaborates a wide variety of historical and 
geographical information, but also sensory and emotional elements, a mapping of the cultural landscape open to multilevel interpretations and emotional investments, that, however, produces an imprint understood by the general public and related to the development needs of a modern society. It is, therefore, a means of raising awareness and commitment to the protection of the cultural landscape. We believe that this is especially important for "disadvantaged", geographically isolated or inaccessible places such as are today, in Greece, the declining mountain and island settlements. The protection of the cultural landscape is certainly not the only parameter of the recovery of such areas but it is a necessary parameter.

In this kind of scientific and artistic mapping and visualization of cultural landscapes our research work is experimented with, in the example of the «revolutionary palimpsests», the settlements that record the events and the spirit of the Greek revolution of 1821. So far, a large group of researchers, students and architects have created about 1000 artistic mappings for 150 of these settlements, in a crowd-mapping project which is performed bottom-up, is democratic, not directed, open to multiple interpretations. The great impact that the project had on the students shows its dynamics for the dissemination of information and the sensitization of the public towards the cultural landscape. Its positive acceptance so far made it possible to plan a big exhibition in September 2021 in Athens.

In this paper, we refer briefly to two examples of the research process: the two most renowned and most inaccessible places of the Greek revolution, the areas of Souli and Mani, of which the network of settlements has been studied and visualised. The relevant cartographic works reveal similarities (in geography, ethnography, and history) but also differences (in the current development process) between the two areas. In the case of Souli, there is a tragic contrast between its fame and prosperity in the early 19th century and its current decline and dereliction. The disobedient Souli that controlled financially and militarily the whole region of Thesprotia, a natural fortress, invulnerable thanks to its mountainous configuration and inaccessible terrain, today is for the same reason abandoned and desolate. From the multifaceted confederation and the heroic Tetrachori with its 400 wells, today only a memory space remains naked, cut off from other uses and networks, the limited attendance of which depends on the tourism of the surrounding areas. Mani, on the other hand, an equally fortified and inaccessible area, with a similar role in the revolution, maintains even today a strong identity, after experiencing a long period of economic and demographic decline which has been interrupted due to tourism. Unlike mountainous Souli, the coastal location of Mani was the advantage that allowed it to be currently in development. However, that kind of evolution was strongly favored by the timely protection of the areas' cultural and natural heritage which the local community still associates with the memory of the revolution.

We could therefore conclude that the protection and promotion of the cultural landscape is only one of the parameters of the development of disadvantaged areas. But it is certainly a parameter of self-respect and self-determination of local communities as part of a world that is not afraid but can give meaning to the differences that make it cohesive. The question is what strategy could combine these differences. We would like to contribute to such a reflection.

Acknowledgements for the research project Revolutionary Palimpsests:

The project was supported by the Hellenic Foundation for Research and Innovation (H.F.R.I.) under the First Call for H.F.R.I. "Science and Society" "200 years since the Greek Revolution" (Project Number: 63).

\section{References}

1. A. Rossi. The Architecture of the City. USA: The MIT Press, (1984). 
2. B. Hillier. The Genetic Code for Cities - is it simpler than we think?, Complexity Theories of Cities have come of Age. Delft, (2009).

3. K. Moraitis. Landscape allocating place through civilisation: exposition and theoretical correlation of the most significant modern approaches concerning landascape. $\mathrm{PhD}$ Dissertation, NTUA, (2012).

4. J. Kimerling, et al. Map Use Reading Analysis Interpretation, Redlands California : Esri Press Academic, (2012).

5. E. Tsakiri, A. Vasilara. Mapping Cultural Cityscapes in the Digital Era and the Century of Complexity, Journal Sustainable Development, Culture, Traditions 1b, (2018). DOI: 10.26341 .

6. A. Bagineta. Local Cultural Development of Sustainable Character. The case of Moschato Cultural Center. Harokopio University. Dept. of Economics \& Sustainable Development. Postgraduate Programme: Sustainable Development, (2009).

7. D. Rokkos. The Intergrated Development of Mountainous Areas. Proceedings of the $3^{\text {rd }}$ Transacademic Conference of NTUA (M.I.R.C.) 7-10/06, 79-140 (2004).

8. E. Relph. Place and Placelessness, London: Pion, (1976).

9. S. Langer. Feeling and Form. A Theory of Art Development from Philosophy in a New Key. New York: Scribners, (1953).

10. G. Bachelard. The poetics of space. Presses Universitaires de France (first published), (1958).

11. R. Govers, F. Go. Place Branding. Global, Virtual and Physical Identities, Constructed, Imagined and Experienced. UK: Palgrave Macmillan, (2009).

12. E. Hobsbawm. The Age of Revolution: Europe 1789-1848. UK: Vintage Books (1962).

13. J.F. Bedard. Cities of Artificial Excavation: The Work of Peter Eisenman 1978-1988. New York: Rizzoli International, (1994).

14. A. Huyssen. Present Pasts. Urban Palimpsests and the Politics of Memory, Stanford: Stanford University Press, (2003).

15. M. Batty, P. Longley. Fractal Cities. A Geometry of Form and Function. London: Academic Press Limited, (1994).

16. H. Hawkins. For Creative Geographies: Geography, Visual Arts and the Making of Worlds. Routledge, (2013).

17. J. Crampton, J. Krygier. An Introduction to Critical Cartography, ACME: An International e-Journal for Critical Geographies 4 (1), (2005).

18. M. Archer, C. Decoteau, P. Gorski, D. Little, D. Porpora, T. Rutzou, C. Smith, G. Steinmetz, F. Vandenberghe. What is Critical Realism?, A Newsletter of the ASA Theory Section Theory 38 (2), 4-9 (2016).

19. A.M. MacEachren, D.R. Taylor (Edt.). Visualization in Modern Cartography. Pergamon, (1994).

20. E. Tsakiri. From multiplicity to complexity. The city image in its visual representations. PhD Dissertation, NTUA, (2018).

21. E. Tsakiri. Poli-Plex-Icon: A design framework for the City Image visualization in the Age of complexity, Urban Transcripts Journal. Visualizing the City 3 2, (2020).

22. G. Génette. Palimpsestes: La littérature au second degré. Paris: Seuil, (1982).

23. K. Moraitis, D. Filippidis. The historical superimposition of cities as a synthetic request for natural design, Proceedings of New Cities over Old ones Conference, Rhodes Island, Greece, 27-30/09, (1993).

24. G. Deleuze, F. Guattari. A Thousand Plateaus: Capitalism and Schizophrenia. USA: University of Minnesota Press, $2^{\text {nd }}$ ed. (1987).

25. Ann Swidler.Culture in Action: Symbols and Strategies, American Sociological Review. Sage Publications 51 (2), 273-286 (1986). 